\title{
Human Resource Competence and Its Impact on Proactive Behavior in Jordanian Commercial Services Companies
}

\author{
Lana Shawqi Al-Awartani ${ }^{1} \&$ Shaker Jaralla Alkshali ${ }^{2}$ \\ ${ }^{1}$ Luminus Technical University College, Amman, Jordan \\ ${ }^{2}$ The world Islamic Sciences \& Education University, Amman, Jordan \\ Correspondence: Shaker Jaralla Alkshal. E-mail: Drshaker55@yahoo.com
}

Received: December 24, 2020

Accepted: January 8, 2021

Online Published: January 22, 2021

doi:10.5539/ass.v17n2p70

URL: https://doi.org/10.5539/ass.v17n2p70

\begin{abstract}
The study aimed to identify the impact of human resource competencies on proactive behavior in Jordanian commercial services companies. The study adopted three dimensions of human resource competencies: knowledge, skills, and attitudes. The study population consisted of (182) managers in Jordanian commercial services companies. The study adopted a comprehensive survey method for managers and (130) questionnaires were obtained, for which the study was conducted. A set of statistical methods were used to analyze the study data, the most important of which is the multiple regression coefficient.

The study found that there are high levels of the dimensions of human resource competencies, and the level of proactive behavior was high. There is a significant impact of human resource competencies on proactive behavior.
\end{abstract}

Keywords: human resources competencies, proactive behavior, commercial service companies, Jordan

\section{Introduction}

The changes in the business environment from time to time, as a result of political, economic and social developments that have a great impact on the organization's determination of the set of means and methods that guarantee its survival and continuity, and enable it to achieve preference and precedence over competitors in the labor market. The success of the organization in facing its competitors needs to be aware of the size of its capabilities, and work to strengthen them, so it is necessary to manage the organization is flexible and dynamic in order to allow itself to adapt to the changes taking place, so that it is able to adapt with various parties and changes to maintain its survival and growth, and to maintain its success.

Here, the importance of strategic success appears in order to enhance the competitiveness of the organization in the market, in a phase characterized by intense competition, and the acceleration of global transformations, such as the globalization of the economy, strategies for collective action, the shift from manufacturing to service economies, mergers and alliances, the development of information and communication systems, and the emergence of companies regional and international (Daoudi \& Mahboub, 2007). The organization's choice of a specific strategy, and its success in implementing it, requires it to carry out multiple practices that guarantee success in what it plans and thinks about in order to reach its goals. Among these practices is its attempt to develop employees' cognitive and skills competencies, and their competencies in building trends and doing work (Al-Asadi \& Talib, 2017). Determining the level of efficiency and effectiveness of the organization and its success comes through the achievement and effectiveness of its employees at all levels, through the efficiency of employees, and their behavior and intellectual activities, they provide a dimension to the practices that allow for thinking creative solutions to the problems that the organization may face (Parker, Bindl, \& Strauss, 2010). Therefore, the need for the organization appears to provide methods and means capable of bringing about a change within it, and this change provides the ability to adapt the organization to the various internal and external changes (Khalil \& Hammoud, 2019), including the proactive behavior of employees, in order to introduce new working methods, or influence the organization's strategy in Its ability to grow, providing a new approach for it to adapt quickly and effectively in the face of unexpected changes in the business environment, where the proactive behavior of workers is the best way towards shifting work to decentralization, flexibility and continuous innovation, taking appropriate solutions to organizational problems, improving conditions and facing 
challenges (Al-Fatlawi \& Al-Kaabi, 2018). Continuity and interaction in light of the changing environment requires flexibility and finding a balance for various business organizations and the various commercial companies operating in the Jordanian environment (Abuzaid, 2018). Based on the above, this study came to identify the impact of human resources competencies on proactive behavior in Jordanian commercial services companies.

\section{Study Problem and Questions}

In light of changes in the business environment that were characterized by speed, scarcity of resources, technological developments, and the occurrence of global crises that affected the global and local economy, which was reflected in the work of various organizations; this has called for adopting new concepts in the success of organizations, based on measures based on them to face external and internal changes, which is called strategic success, which seeks to build a management system characterized by the ability to adapt, grow and survive. Balour (2010) pointed out that human resources are an important and fundamental factor in the success and continuity of the organization, and neglecting human resources, not preparing them and not providing a work environment that positively affects the morale of workers, imposes huge losses on the organization, given that these human resources are able to seize opportunities and face challenges. From here emerges the need to develop and develop the human competencies of the organization, as Plomp et al. (2016) see that human resources need diversity and plurality in skills and behavior, which requires dispensing with old methods and developing new ones that are compatible and consistent with The new design of work in light of future conditions and challenges by training workers, enhancing their competencies, taking the initiative and adopting the orientation for activities that exceed the actual work requirements, and creating new opportunities that involve challenging the status quo instead of negatively adapting to present initiatives, which is known as proactive behavior. The study will try to answer the following questions:

- What is the level of availability of human resources competencies in Jordanian commercial services companies?

-What is the level of availability of proactive behavior in Jordanian commercial services companies?

- What is the impact of human resource competencies on proactive behavior in Jordanian commercial services companies?

\section{Study Importance}

The current study derives its importance from the main aspects it studies in the study community, namely the Jordanian commercial services companies, and the positive aspects that can be promoted, or the negative aspects that can be avoided and addressed, hence the importance of the current study is as follows:

Theoretical importance: Those who follow the administrative literature related to the competencies of human resources will find that there is a lack of this aspect. Through research and presentation of previous studies, it is evident that there is a difference in the interpretation of the content of these variables, which indicates the existence of a cognitive problem that requires preparing and setting scientific and cognitive limits for it.

Therefore, this study seeks to contribute to the preparation of an intellectual and theoretical framework for the subjects of the study, to provide a scientific contribution regarding its variables, and to contribute to the enrichment and strengthening of the management library that lacks research and studies on the subject of human resource competencies and the proactive behavior of employees.

Applied importance: This study represents an attempt to contribute to identifying the importance of human resources competencies for business organizations in providing the elements of proactive behavior for employees, making them more aware and aware of what they are doing. This study also seeks to provide a simple effort and add a qualitative addition to the applied aspect of business organizations, by revealing the impact of human resources competencies on the proactive behavior of Jordanian commercial services companies, which it is hoped will open new horizons for researchers within their variables.

The importance of the researched sector: The commercial services sector constitutes a basis for building and developing the economies of countries, and all economic indicators clearly reveal that the commercial services sector has become a basic pillar of economic development. Services provide a number of intermediate inputs, and have a pivotal role in coordinating production processes, and the annual report of the Central Bank of Jordan for the year (2018) indicates that the relative importance of the service sector in the gross domestic product has stabilized at almost constant base prices at its level in (2017) of (63\%). Also, the service production sectors still hold the largest share of the GDP growth rate at constant base prices, as they contributed (4.1) percentage points (out of a growth rate of (2.0\%) (Jordan Central Bank, 2018). 


\section{Study Objectives}

This study seeks to achieve the following objectives:

- Knowing the level of human resource competencies in Jordanian commercial services companies.

- To identify the level of proactive behavior in Jordanian commercial services companies.

- Knowing the impact of human resource competencies on the proactive behavior of Jordanian commercial services companies.

\section{Theoretical Framework}

\subsection{Human Resource Competence}

The human resource is one of the most important resources that any organization can possess, and therefore all efforts from institutions and individuals have directed towards researching how to achieve optimal use of the human element, which helped the emergence of a methodology of competencies in human resource management, which deals with interest and search for characteristics which must be owned by the employee, and provide the employee with an indication of the behaviors and procedures that will be appreciated, recognized and rewarded, and can help employees to work effectively individually or as a team, which leads to improving the overall performance at work, and improving the appropriate career path for the individual to achieve his happiness and achieve the goals of the organization (Ibidunni, 2020).

Human resources are a major contributor to production processes and the knowledge economy, as organizations of all fields maintain human resources as valuable assets that help in growth, and evaluate the performance of the organization, through programs that provide the necessary training and support to maintain the workforce and involve individuals in the daily activities of the organization and contribute with their skills. And their knowledge for the benefit of the organization, which leads to an increase in interactions and relationships between employees and this, is reflected in increased confidence, job satisfaction, cooperation and exchange of information that directly encourages employees to be contributors to the generation of sustainable value for the organization (Dom \& Ahmad, 2020).

Human resources are the real and main wealth of nations. The interest in the human element has increased dramatically due to its capacity for creativity, innovation, and development. Where its importance is embodied in modern organizations as the real basis for creating a competitive advantage for the organization, through the stock of skilled, qualified and experienced human resources that the organization possesses, which enables it to perform its activities more efficiently (Al-Salem, 2014, p. 28). Raising the level of technical skills of workers and improving them, is increasingly important for two reasons: new technology, and new structural designs in organizations (Robbins \& Judge, 2015, p. 551). Lucia and Leibsinger (2000, p. 1) described the competencies of human resources as a set of personal, scientific and practical traits and qualifications that enable employees to achieve outstanding and standard performance rates that exceed normal rates. Shanda and Kabra (2002, p. 159) also indicated that it is the ability to perform efficiently within the work environment, as well as the ability to respond to challenges within the scope of the work environment. Al-Zahir (2009, p. 37) defines the competencies of human resources as a set of characteristics that contribute to the effective performance of the human resource and enable the organization to achieve business strategies in the competitive market. Bani Hamdan and Idris (2009, p. 268) indicates that the competencies of human resources are a set of knowledge, skills, values and attitudes possessed by the employee, which unite together to form a specific behavior that is required to perform a number of job tasks efficiently and effectively, where the process of renewing knowledge, developing skills and adhering to constructive values and trends Appropriateness to the organization, one of the essentials for the employee to enjoy job.

Al-Ta'i and Al-Waeli (2018, p. 77) indicated that there are three entrances to determine job merit, which are as follows:

1. The scientific approach: as it is based on analyzing and describing the role. This analysis and description results in identifying the skills, knowledge, and attitudes required performing the role, and these competencies are evaluated by criteria that are often behavioral.

2. Psychological approach: It is based on the characteristics of the personality with its technical knowledge, behavioral, motivation, and intelligence skills, as it is considered the best means for predicting professional success.

3. Business approach: where merit is a competitive advantage, higher and better performance determines job competencies. 
The concept of building human resources competencies includes two types: the first type, which includes narrow definitions, which mainly focus on strengthening the economic and technical aspects of organizations, and the second type, which is the more comprehensive definition, which includes the following levels (Al-Asadi \& Talib, 2017):

- The individual level: It is the level at which the conditions are created to build and enhance knowledge and skills for individuals, and allow them to participate in the learning process and adapt to change.

- The institutional level: This includes building the competencies of local organizations and supporting them in forming sound policies, organizational structures, and effective methods of management and control.

- The societal level: the level that supports the creation of an interactive public administration that learns equally from its work from feedback and is used in building competencies for the development of managers (Saudi, 2020).

The broader definition of competency building means the process of developing and enhancing the skills, processes and resources that organizations and societies need to survive, succeed, adapt and thrive in the fast-paced world, as it includes elements that give liquidity, flexibility and jobs to adapt to the changing needs of customers (Abbas, 2020). Building competencies includes many characteristics and not only training, such as human resource development, organizational development, setting up administrative structures, processes and procedures, developing the institutional and legal framework, and making legal and organizational changes to enable organizations at various levels and sectors and work to enhance their capabilities (Al-Asadi \& Talib, 2017) .

Researchers divided decadents into a number of types, as Bani Hamdan and Idris (2009, pp. 261-264) divided them into distinctive merits, and essential merits. Al-Ta'i and Al-Waeli (2018, p. 61) classified them into the merits of personality traits, leadership and management competencies, and essence competencies. While Lucia and Leibsinger (2000, p. 88), Chandra and Cobra (2002, p. 74) view human resource competencies as being comprehensive to the types of human competencies and are categorized into productive merits, artistic merits, leadership competencies, and personal merits. There are those who classified them into knowledge competencies, skill competencies, and trends related to trends (Al-Asadi \& Talib, 2017), and this study will adopt the last classification to measure the competencies of human resources.

- Knowledge competencies: The interest of researchers and specialists in knowledge has increased as a result of organizations' different activities seeking to link all their operations and investments with knowledge, encouraging individuals to find knowledge in various methods and means, and employing this knowledge to achieve a competitive advantage for the organization, in light of technological and informational developments, global innovations and the digital revolution (Ponisciakova, 2020). The essence of using knowledge in organizations is their ability to form and practice cognitive processes, by focusing on employing the accumulation of knowledge experience present in the organization, and benefiting from interactions between members of the organization who possess knowledge and using it in organizational processes (Bontis, 2013). Gloet and Samson (2020) emphasizes that knowledge is based on creating an environment and culture in which knowledge can develop and encourage the development of talent, creativity and innovation, while Koenig (2009) pointed out that knowledge is related to the organizational culture. On the other hand (Ibidunni, 2020) believes that knowledge can be viewed as a strategy to improve organizational performance by helping workers share and apply information. Knowledge represents a mixture of skill, values, experience, and information about the surrounding environment more than it is a skill of prediction and intuition, it is the sum of data, information and practices and a full awareness of relationships and processes, and they arise through the mind and vary between individuals according to their understanding of the nature of things around them and the extent to which they benefit from it (Al-Salem, 2014, p. 29).

- Skill competencies: The skill and competence of human resources represent an important element in the organization, by contributing to the development and improvement of the organization's efficiency, and making it capable of facing challenges and building an effective and successful strategy (Al-Salem, 2014, p. 29). Skill is defined as the level of an individual's proficiency in performing a specific task, and skills may be determined by self-awareness, setting goals, and emphasizing time and conflict management, as part of human competencies in addition to creativity and innovation (Change, Li, \& Chen, 2015). Dom and Ahmad (2020) pointed out that among the reasons for the failure of organizations is the lack of skilled workers, in addition to the lack of strong relationships between workers and employers, and the synchronization of the needs and goals of workers with the goals of the organization, so the adaptation of the organization's strategy and efforts to provide skilled workers and enhance their skills will accelerates efforts to stabilize and develop the organization, in addition to 
employee commitment to achieve the organization's goals

Human skills can be divided into a number of sections as follows:

* Technical skills: Refers to skills based on specialized knowledge, and requires specific knowledge or experience acquired through training or practical experience (practice), in order for the individual to perform what is required of him, as this skill allows the effective use of methods and the tasks to be performed appropriately, which guarantees the achievement of the goals of the organization (Abbas, 2003, p. 42). Skills include openness to experience, awareness and openness, and conscience. Awareness and openness influence participation in development activities, the ability to display positive emotions while dealing with job complexity, and aids in developing possible and innovative HR strategies. Individuals who have a great openness to acquiring experience are eager to learn, and appreciate the need to develop capabilities for success in the future, as they set high standards of performance for themselves, and enable them to take a proactive role to change the course of work, which helps them to develop experience in designing policies and processes, which is reflected On the success and development of the organization (Srikanth, 2019).

* Intellectual skills: are the skills that represent the specific mental processes practiced and used by individuals intentionally to process information and data, to achieve multiple goals, such as remembering information and describing things, taking notes, predicting and evaluating processes, solving problems, and reaching conclusions. They are related to the vision of the organization as a whole and its relationship. With the external environment which determines the relative priorities of the organization, and examples of intellectual skills: planning skill, leadership skill, and decision-making skills (Abbas, 2003, p. 42). In addition to the problem-solving skill in business analysis, which includes active listening in obtaining a consistent understanding of the problem, identifying specific data that can inform the public in solving the problem, the ability to respond to confronting the problem, rapid analysis of the context and environmental factors, and providing solutions to de

* Communication skills: These are the skills of the individual's work with others as a member of the organization, and these skills are concerned with the individual's ability to deal with others in a good way, find a spirit of teamwork they have, and how to influence their behavior, attract them and cooperate with him, and direct them in the direction that achieves the goals of the organization (Abbas, 2003, p. 42). Skills are among the effective tools in the processes of change, development and interaction between individuals and groups, as the more information, ideas and experiences expand, the more they need communication channels to transfer them and complete the process of communicating them to individuals or work teams (Robert et al., 2020). Communication skills include competence in recognizing the requirements of working with others as individuals or groups, working to respect the personality of others, building morale, achieving psychological satisfaction, and generating trust and mutual respect among individuals (Maher, 2013, p. 39).

- Attitude competencies: Attitudes have an important impact on the behavior of workers and their motives, as they drive workers towards the work itself, towards their supervisors, and towards the implementation of their duties and tasks (Al-Salam, 2014, p. 31). What is the individual's feeling about an issue, when the individual says (I love my job), he expresses his positions on the work, and in order for the individual to understand the trends, he must take into account the basic components that make up them (Al-Asadi \& Talib, 2017). Bontis (2014) believes that trends indicate the organization's ability to possess human cadres with scientific training, acquired practical experience, awareness of laws and work standards, and its possession of conviction and enthusiasm for work. Change et al. (2015) defines it as one of the states of nervous and mental preparation and preparedness regulated by experience, and it has the effect of directing the individual's responses towards different things and situations.

\subsection{Proactive Behavior}

Proactive behavior is defined as an action directed at the self-future, which aims to change and improve the situation. It aims to bring about constructive change, and contributes positively to strengthening the individual or team, and is reflected in the results of the level of performance in the organization, including individual performance, career success, team work, and organizational processes (Parker \& Collins, 2010). From Robbins and Judge (2014, p. 142) point of view, proactive people are people who identify opportunities, demonstrate initiative, take action, and persevere until real change occurs, compared to others who react negatively to situations, and try to find positive opportunities for change in their environment, regardless of limitations (Or obstacles): Reactiveness refers to taking the initiative in improving the current conditions, as it involves determining the existing situation instead of adapting passively to make concessions, as it is considered as a self-initiative in which there are future-oriented actions that aim to change and improve the self or the current situation (Liu et al., 2017). The proactive behavior at the individual level refers to the self-launch, and to work 
on the individual's focus on the future, which aims to change the external situation, such as improving work methods, or changing some aspects of it, and focusing on performing the basic task, or on adapting to the future (Parker et al., 2010). Parker and Collins (2010) notes that most of the concepts of anticipatory behavior include three elements: Anticipation, which means early anticipation of a specific future situation and the element of control and causing change, and the third element is the initiative or self-initiation. Al-Atwi and Al-Hussaini (2018) believe that the concept of proactive work behavior differs from both the concept of creativity and the concept of adaptive work behavior. As the creative behavior is associated with originality and modernity while the proactive action behavior does not necessarily entail modernity and originality, however, the creative behavior and the proactive work behavior are linked with each other through their focus on the future and focus on change. Adaptive work behavior differs from proactive work behavior. Adaptive behavior is based on the individual's modification of his behavior in line with the situation, meaning that it represents a response to the existing change, while proactive behavior represents the initiative to make and initiate change, and they are linked with each other through their association with the environment that is characterized by uncertainty and prediction. Ghitulescu (2018) believes that proactive behavior includes initiating improved work, procedures, requesting feedback, or actively adapting to new environments. Many organizations view employee proactivity as crucial to staying in a dynamic work environment, and it represents an important source of competitive advantage for organizations, as well as It has been linked to positive behavior and results such as high job performance, innovation, entrepreneurial success, organizational effectiveness, and enhanced employee feelings of satisfaction.

Guan and Huan (2018) classify anticipatory behavior by patterns into personality anticipatory behavior, dynamic process, and behavior; Personal behavior means a stable personal and behavioral trait, which is the tendency of individuals to take measures to influence their surroundings, but from a dynamic process perspective, employee proactive is characterized by actions that include the dynamic process of anticipation, planning and action directed towards future influence, and through this, employees can change and advance the future development direction for themselves or the organization. From the perspective of behavior, it means the spontaneous behaviors of employees, including expectations, plans, and arrangements to improve personal quality, and better achieve organizational goals.

The importance of proactive behavior; where the proactive behavior of workers is necessary to achieve success for organizations, especially in light of the dynamic environment in which they live, as it is characterized by increasing challenges, scarcity of resources, and the need for continuous improvement, and through this highlights the importance of proactive behavior among employees in the organization, it helps to improve work relations It makes attitudes more positive, increases feelings of empowerment, and increases career success. On the other hand, it is important for the organization as it maintains its goals through anticipation, planning and problem-solving in the work environment, searching for ways to change the current circumstances, and helping to enhance the benefits of relationships between colleagues and partners, resulting in high-level relationships at work, which is reflected in the improvement of effectiveness of the organization (Ghitulescu, 2018).

The review of previous studies related to the concept of anticipatory behavior showed that it has a number of dimensions, as follows (Al-Fatlawi \& Al-Kaabi, 2018):

1. Prevention of problems: it means dealing with the process of preventing the occurrence of challenges and obstacles in the work environment through the worker planning for the future and thinking about the roots that cause them (Parker \& Collins, 2010) The prevention of problems relates to the future self-response to prevent the occurrence of the problem and address its root causes in an unusual way. And nonstandard any prevention from happening in the first place (Dyne, Soon, \& Isabel, 2003). Prevention of problems is a self-action based on predicting problems and working to prevent their occurrence and recurrence in the future. Therefore, workers try to prevent the occurrence of challenges and obstacles in the work environment by the worker planning for the future, and thinking about the roots of the problems and challenges (Parker \& Collins, 2010).

2. Voice behavior: Voice behavior represents informal and voluntary communication by the worker that carries with it ideas, suggestions, concerns, information about problems, or opinions related to work issues, sent to people who are able to take appropriate actions, with the intention of achieving improvement or change. (Liu et al., 2017). Dyne et al. (2003) that vocal behavior refers to the active efforts of employees to talk about important issues and to make innovative suggestions for change, and in this case it is considered positive behavior, while it can represent negative behavior if there is a complaint or personal criticism. The phonemic behavior is the sending of a message and expressive work that includes constructive challenges to improve the work environment, and it is contrary to the concept of organizational silence, which indicates that the worker does not send his voice to the relevant authorities when he has proposals, or information, and different points of view that 
could benefit the work environment. (Morrison, 2014, 174). Liu (2010) believes that the voice of the worker plays a critical role in the organization as organizations nowadays rely on more innovation and rapid responses in order to survive in the markets, which motivates the organization to encourage employees to express their concerns and opinions freely, and that organizational issues such as individual factors Such as satisfaction, and situational factors such as the psychological well-being of the individual make vocal behaviors beneficial, especially if they are overt and explicit. In spite of that, the voice behavior may face many risks if it is considered by the management as a kind of challenge, or it can be interpreted as a lack of cooperation or opposition, and inquiring about the current situation may create feelings of discomfort in the management of the organization. Andiyasar et al. (2017) describes that in the event that the organization does not listen to the voice of the worker, the information will be lost, which will be reflected in the organizational performance, so the organization must encourage employees to express their ideas through their feeling that they are part of the organization, and thus the employee becomes willingness to make additional efforts to protect and strengthen the organization and work, which will enable the organization to survive, self-correct and face future challenges, especially if the vocal behavior aims at improvement and constructive expression instead of criticism. It also believes that individual factors affect the vocal behavior such as habits, skills and knowledge required, which will affect the quality of the voice relations between the employee and the supervisor, as it represents a strong mediator between them.

3. Taking responsibility Morrison and Phelps (1999) are the first to introduce the term responsibility assumption as part of the additive's behavior they are constructive volunteer efforts undertaken by individuals in the work environment with the aim of making an organizational job change that includes how work is carried out in the field of their jobs, their work units or their organizations, and accordingly, assuming responsibility is a voluntary behavior, not mandatory by the organization aimed at improving the internal work environment. Al-Atwi and Al-Hussaini (2018) define taking responsibility as the constructive volunteer efforts that the individual undertakes in the workplace to make a job change in how the work is carried out in the context of the job or organization. Improving the internal work environment of the organization, and taking responsibility by workers means that they initiate appropriate new business procedures in the organization regardless of the existing and applicable work rules (Parker \& Collins, 2010).

4. Individual innovation: the tendencies of the individual in the workplace intentionally and purposefully to present new ideas or methods (Parker et al., 2010). It is also defined as the behavior involved in creating and implementing ideas, identifying opportunities, generating new ideas, new approaches to working, and implementing these ideas. Parker and Collins (2010) shows that individual innovation means the individual's tendencies in the workplace intentionally and purposefully to present new ideas or methods. The concept of individual innovation with responsibility and the voice of the worker in terms of its focus on improving the work environment, and differs in its focus on originality and modernity.

\section{Literature Review}

Researchers have been interested in studying the proactive behavior of employees, because of its importance in the performance of the organizations in which they work, in terms of providing innovative products, increasing performance, and achieving competitive advantage. In the study of Qandil et al. (2020) which focused on analyzing the role of smart organization characteristics on achieving entrepreneurial preparedness by adopting proactive work behaviors. It concluded that adopting proactive work behaviors has an effective effect in enhancing the relationship between the characteristics of the smart organization and achieving the pioneering preparedness of the company in light of the growing competitiveness. In a study conducted by Elsaied (2019a), its results indicated that there is a positive influence relationship between supportive leadership and proactive personality in vocal behavior, and a positive significant relationship between supervisor support and employee vocal behavior. In another study conducted by Elsaied (2019b), its results indicated that there is an interaction between the supportive leadership and the proactive personality, which negatively affects the employee's vocal behavior, and that the employee's advocacy mediates the relationship between the supportive leadership and the employee's voice behavior. On the other hand, the results of the study of Al-Fatlawi and Al-Kaabi (2018) showed the availability of quality social relations and proactive behavior in organizations. The study also concluded that there is a significant negative effect represented by the effect of the quality of social relationships on proactive behavior. As for Auja (2018), its results indicated that there is an effect of proactive personality on the creative performance of employees. The findings of the study of Al-Atwi and Al-Hussaini (2018) showed that the culture of error management has a significant effect on psychological empowerment and proactive work behavior, and that psychological empowerment mediates the relationship between the culture of error management and proactive work behavior. Fu et al. (2020) study indicated that participatory leadership positively affects team 
work, and that participatory leadership influences employees' adaptive performance through proactive behavior. In another study conducted by Farooq et al. (2020), it was concluded that there is a positive significant relationship between the proactive personality and creativity, and there is also a positive relationship between the proactive personality, motivation and initiation. As for the study of Liao et al. (2019), it has been shown that there is a triple interaction effect between the narcissism of the perceived leader, the quality of the exchange between the leader and the subordinates, and the identification of the leader, which negatively affects the behavior of the proactive employee, and when the quality of exchange between leader and subordinates, and leader's identification at a high level, the relationship is negative between the leader's perceived narcissism and the employee's proactive behavior. In another study conducted by Huan and Guan (2019), its results indicated that human resource management practices positively correlate with proactive behavior, and that there is a significant effect of human resource management practices on proactive behavior, and a direct effect of human resource management practices in organizational support. The results of Choi and Hwang (2019) study showed that there is a high positive influence of the two dimensions of positive social personality (sympathy and helping others) and proactive personality in client citizenship behaviors. The customer's citizenship behaviors increase the customer's satisfaction and thus increase his intent to continue the relationship. As for the study of Roopak et al. (2019), its results indicated that the congruence and harmony between the leader and his followers in the proactive personality leads to high levels of creativity for the followers, and encourages them to present creative ideas, and that there is a positive relationship between the match between the proactive personality of the leader and his followers with the creativity of the followers. In a study conducted by Alom (2018), its results showed that some dimensions of organizational culture are related to the value of proactive transparency, which in turn is related to the behavior of proactive transparency on the front lines of public bureaucracies in organizations, and that there is an effect of the behavior of proactive transparency in the organizational structure, and that the behavior of proactive transparency determines the direction towards external accountability. The results of Liu, Joycekor et al. (2017) indicated that there is an upward relationship between the performance of the proactive entrepreneurial behavior and the achievement of advanced performance for a new product, and there is an upward relationship between the proactive entrepreneurial behavior and the ability to innovate. The study by Plomp et al. (2016) showed that there is a positive relationship between proactive personality and employee well-being, and that proactive employees can enhance their well-being by redesigning proactive work and developing their skills and abilities related to their jobs. The results of Jiang and Gu (2015) study showed that there is a positive relationship between sense of responsibility, proactive personality and employee creativity, and a positive relationship between basic self-evaluation, developmental reactions to proactive personality and sense of responsibility for change.

\section{Hypothesis}

There is no significant impact of human resource competencies on proactive behavior in Jordanian commercial services companies.

\section{Methodology}

\subsection{Sample}

The study population included all the managers in the Jordanian commercial services companies registered in the Amman Stock Exchange of (9) companies, in which (182) managers are employed, as shown in Table 1. The questionnaire was distributed to all the managers of the study community through direct visits made by the researcher to these companies, in cooperation with the human resources departments therein, and after the completion of the distribution process (139) questionnaires were retrieved and after checking the retrieved questionnaires (9) questionnaires were excluded for the lack of the required data and accordingly, the remainder of the questionnaires, suitable for analysis, were (130) questionnaires.

\subsection{Instrument}

The researchers used the questionnaire as a tool for collecting primary data, and the study variables and measures were guided, in addition to being guided by previous similar sources and studies related to their variables, and the study tool was designed as follows:

The first part: this part included the items that measure the independent study variable (human resources competencies). The items of the dimensions of this variable have been developed after reviewing a number of references (Al-Taan, 2018; Al-Asadi \& Talib, 2017; Abuzaid, 2018; Srikanth, 2020).

Part Two: this part includes the items that measure the modified study variable (proactive behavior). Items of the dimensions of this variable were developed after reviewing a number of studies (Al-Rubaie \& Ali, 2018; 
Al-Fatlawi \& Al-Kaabi, 2018; Auja, 2018; Elsaied, 2019; Farooq et al., 2020).

\section{Results}

To ensure the reliability of the study tool's reliability, the value of Cronbach's Alpha Coefficient was calculated to indicate the extent of the internal consistency of the study items, and to indicate the quality of the construction of the items of the questionnaire and the strength of their cohesion. Table (1) shows the reliability coefficient for the study measures, and alpha values ranged between $(0.71)$ as the lowest value, and $(0.89)$ as the highest value. This explains that all alpha values have exceeded the minimum acceptable ratio for the purposes of statistical analysis as alpha is considered equal to or greater than (0.70) is acceptable in human studies (Al-Najjar et al., 2017, p. 151).

Table 1. Descriptive statistical results

\begin{tabular}{ccccccccc}
\hline Variable & Items & Alpha & Mean & Std. & $\begin{array}{c}\text { Knowledge } \\
\text { competence }\end{array}$ & $\begin{array}{c}\text { Skills } \\
\text { competence }\end{array}$ & $\begin{array}{c}\text { Attitude } \\
\text { competence }\end{array}$ & $\begin{array}{c}\text { Proactive } \\
\text { behavior }\end{array}$ \\
\hline $\begin{array}{c}\text { Knowledge } \\
\text { competence }\end{array}$ & 5 & 0.71 & 4.01 & 0.73 & 1 & & & \\
$\begin{array}{c}\text { Skills } \\
\text { competence }\end{array}$ & 5 & 0.80 & 3.95 & 0.68 & 0.49 & 1 & & \\
$\begin{array}{c}\text { Attitude } \\
\text { competence }\end{array}$ & 5 & 0.89 & 4.06 & 0.76 & 0.61 & 0.39 & 1 & \\
$\begin{array}{c}\text { Proactive } \\
\text { behavior }\end{array}$ & 9 & 0.85 & 3.96 & 0.63 & 0.58 & 0.73 & 0.64 & 1 \\
\hline
\end{tabular}

Table 1 refers to the mean averages of human resources competencies in Jordanian commercial companies, which ranged between (3.95-4.06), where attitude came in first place and they had the highest means average, which reached (4.06), which is at a high level, and followed in second place knowledge, with mean average of (4.01), which is of a high level, and skills came in third place with mean average of (3.95), which is at a high level. The table shows that the mean averages of proactive behavior ranged had a total mean (3.96), which is within the high level.

Table 2. Impact of HR competence on proactive behavior

\begin{tabular}{|c|c|c|c|c|c|c|c|c|c|c|}
\hline \multicolumn{2}{|c|}{ Model Summery } & \multicolumn{3}{|c|}{ ANOVA } & \multicolumn{6}{|c|}{ Coefficient } \\
\hline $\mathrm{R}$ & $\mathrm{R}^{2}$ & $\mathrm{~F}$ & Sig. F & $\mathrm{DF}$ & Variable & $\mathrm{B}$ & Std. Error & Beta & $\mathrm{T}$ & Sig. T \\
\hline \multirow{3}{*}{0.64} & \multirow{3}{*}{0.41} & \multirow{3}{*}{142.36} & \multirow{3}{*}{0.00} & \multirow{3}{*}{3} & Knowledge competence & 0.64 & 0.05 & 0.47 & 3.83 & 0.00 \\
\hline & & & & & Skills competence & 0.57 & 0.06 & 0.39 & 3.27 & 0.00 \\
\hline & & & & & Attitude competence & 0.33 & 0.04 & 0.22 & 2.77 & 0.00 \\
\hline
\end{tabular}

Table 2 shows the results of multiple regression analysis of the impact of human resource competencies with their dimensions (knowledge, skills and attitude) on proactive behavior in Jordanian services companies. The value of the correlation coefficient is $(\mathrm{R}=0.64)$ this indicates a relationship between human resource competencies and proactive behavior. While the value of the coefficient of determination was $\left(\mathrm{R}^{2}=0.41\right)$ this means that human resources competencies explained $(41 \%)$ of the variance in proactive behavior and the value of $\mathrm{F}$ was (142.36) at a significant level (Sig. $=0.00$ ), which indicates the existence of an impact significant for human resource competencies on proactive behavior.

The transactional table shows that there is an impact on the dimensions of human resources competencies on proactive behavior, where the value of B for knowledge reached (0.64) with a standard error $(0.05)$ and the value of $\mathrm{T}(3.83)$ at the level of significance (Sig. $=0.00)$, while the value of B for skills reached $(0.57)$ and a standard error (0.06), the $\mathrm{T}$ value (3.27) at the level of significance (Sig. $=0.00)$, while the value of $\mathrm{B}$ for attitude was (0.33), a standard error (0.04) and the $\mathrm{T}$ value (2.77) at the level of significance $(0.00)$. Based on the results of the multiple regression analysis, the null hypothesis cannot be accepted, and the alternative hypothesis that states the following:

There is significant impact of human resource competencies on proactive behavior in Jordanian services companies.

\section{Discussion}

The results of the descriptive analysis that were conducted on the competencies of human resources (the independent variable) showed that the levels of relative importance of the competencies of human resources in 
their dimensions (knowledge, skills and attitude) were all high, and the attitude came first in terms of importance among the rest of the dimensions and at a high level, while knowledge came in second place in terms of importance and at a high level, and skills came in third and last place among the dimensions of human resources competencies in terms of importance and at a high level as well. This can be attributed to the fact that attitude affect the behavior of individuals in the work environment, especially in specific areas such as delay, and belonging to the company. In addition to the fact that the development of the company needs to enhance the feelings and attitudes of the employees and make them feel comfortable with specific issues, such as changing the systems of working hours or the number of days in order to ensure the success of this development, which is in the process of the strategic success of the company. Knowledge came in second place, which indicates the ability of companies to create a knowledge base for employees. The system provides the core competencies of the organization and the possibility of activating its competitive strength because of its need for a knowledge balance among workers that contribute to the use of productive energies at all levels effectively and efficiently, which provides ideal solutions. The problems facing employees, and enabling them to provide innovative and creative services to clients in order to achieve the company's success. While the skills came in the third and last place in terms of ranking among the dimensions of the human resources competencies, and it can be explained that the skills of the employees of the company guarantee the creation of a productive and cooperative work environment appropriate to the success of the company, in addition to its contribution to creating important links with customers in order to achieve the competitive advantage of the company.

This result supports the conclusion of the study of Al-Asadi and Talib (2017), which indicated an increase in the competencies of human resources in the organization.

The results of the descriptive analysis of proactive behavior indicated that the level of materiality was high, and these results can be interpreted in light of the averages that were reached through the statistical analysis process, to the importance of proactive behavior in achieving success for the company, especially in a work environment characterized by dynamism and the presence of increasing challenges, the need for continuous development, as proactive behavior improves relations between employees, in a more positive way, which achieves the goals of the company and is reflected in improving its effectiveness.

This result supports the findings of the study of Al-Fatlawi and Al-Kaabi (2018), which indicated that there are high levels of proactive behavior dimensions for employees. It also agreed with the results of the study of Awja (2018), which concluded that there are high levels of proactive personality behavior among employees. It also agreed with the results of the Roopak (2019) study, which provided evidence for the followers. The harmony and congruence between the leader and his subordinates in the proactive personality leads to high levels of creativity for the followers.

There is a significant impact of human resource competencies on proactive behavior in Jordanian commercial services companies. This may be due to the fact that the group of knowledge, attitudes and skills of the employees of the companies contribute to the processes of anticipation and response to early warning signals, and it deals with various threats, and it constitutes a state of optimal exploitation of the opportunities available to the company.

This result supports the findings of Elsaied (2019a), whose results indicated that an interaction between supportive leadership and proactive personality, which negatively affects the employee's vocal behavior, is that employee advocacy mediates the relationship between supportive leadership and employees' vocal behavior. There is a positive significant relationship between supervisor support and employee voice behavior, and the results of Huan and Guan (2019) study, in which it was stated that there is a significant impact between human resource management practices and proactive behavior.

\section{Recommendations}

Through the findings of the study and the aforementioned conclusions, the researcher provides a set of recommendations for decision-makers in Jordanian commercial services companies, namely:

1. The departments of Jordanian commercial services companies in general, and their human resources departments in particular, establish a clear and specific policy for the incentive system that the employee will receive during his career by developing regulations, instructions and the foundations for this, and that they are circulated to employees by all available means such as: flyers and brochures, Emails, lectures, workshops, etc.).

2. The departments of Jordanian commercial services companies should work continuously to train employees, and pay special attention to that in order to develop their job competencies in line with changes in the work 
environment.

3. The departments of Jordanian commercial services companies establish a specialized unit dealing with continuous innovations.

4. Strengthening the management of Jordanian commercial services companies, the transformational leadership style, by generating a renewed vision towards the future of the company, and providing all that is required to bring about change throughout the company, whether in terms of technical, financial, marketing or administrative requirements.

\section{References}

Abbas, S. (2003). Human resource management is a strategic approach. Jordan, Amman: Wael Publishing and Distribution House.

Abuzaid, A. N. (2018). Employee empowerment and its role in achieving strategic success: A practical study on Jordanian insurance company. Jordan of Business administration, 14(4), 641-657. https://doi.org/10.35516/0338-014-004-006

Al-Fatlawi, M. H. A.-S., \& Al-Kaabi, H. S. M. (2018). The impact of quality social relationships on employee's proactive behavior (An analytical study of employee sample opinions in Karbala Cement Factory). Journal of Administration and Economics, 7(26), 95-126.

Al-Najjar, F., Al-Najjar, N., \& Al-Zubi, M. (2017). Methods of scientific research: an applied perspective (4th ed.). Jordan, Amman: Al-Hamed House for Publishing and Distribution.

Alom, Md., \& Morshed, H. (2018). Proactive transparency and outward accountability of frontline public bureaucracies. International Journal of Productivity and Performance Management, 67(4), 611-628, https://doi.org/10.1108/IJPPM-08-2016-0169

Al-Rubaie, M. T., \& Ali, S. H. (2018). Proactive strategic direction and its impact on strategic performance: An applied study in the Iraqi Ministry of Transport and its subsidiaries. Al-Gary Journal, 15(2), 285-302.

Al-Salem, M. S. (2014). Contemporary human resource management: An integrative strategic approach (2nd ed.). Jordan, Amman: Athraa for Publishing and Distribution.

Al-Taan, H. F. (2013). The impact of human resources management strategies on achieving strategic success: A field study in the Ministry of Transport. Aldenanir Journal, 1(3), 204-256.

Al-Taie, H. S., \& Al-Wali, D. A. (2018). Management of competencies and talents. Jordan, Amman: Al-Yazuri House for Publishing and Distribution.

Al-Zahir, N. (2009). Knowledge management. Jordan, Amman: Wall for Publishing and Distribution.

Andiyasar, A., Matindas, R., \& Riantoputra, C. (2017). Voice behavior: The role of perceived support and psychological ownership. The South East Asian Journal of Management, 11(1), 1-24. https://doi.org/10.21002/seam.v11i1.7735

Aujah, A. M. (2018). The proactive personality and its reflection on workers creative performance. An exploratory study of sample opinions of nursing staff working in the Middle Euphrates Hospital in Najaf. The Journal of Management and Economics, 7(25), 140-164.

Bontis, N. (2013). National intellectual capital index. Journal of Intellectual Capital, 5(1), 13-39. https://doi.org/10.1108/14691930410512905

Chandra, S., \& Cobra, A. (2002). Human resource strategy. Egypt, Cairo: Dar Al-Fajr for Publishing and Distribution.

Choi, L., \& Hwang, J. (2019). The role of prosocial and proactive personality in customer citizenship behaviors. Journal of Customer Marketing, 36(2), 288-305. https://doi.org/10.1108/JCM-01-2018-2518

Chuange, H.-M., Liu, M.-J., \& Chen, Y.-S. (2015). The effects of human resource capability and internal customer satisfaction on organizational effectiveness. International Journal of Distributed Sensor Networks, 1-10. https://doi.org/10.1155/2015/835194

Daoudi, Al-T., \& Mahboub, M. (2007). Enhancing the competitiveness of the organization by achieving strategic success. Journal of the Human Sciences, (12), 37-56.

Dom, F., \& Ahmad, A. (2020). The importance of human capital management in developing quality human capital. Proceeding: Putrajaya International Conference on Advanced Research (PJIC2020), Putrajaya, 
Malaysia, 267-337.

Dyne, V., Soon, A., \& Botero, I. C. (2003). Conceptualizing employee e-silence and employee voice as multidimensional constructs. Journal of Management Studies, 40(6), 2200-2380. https://doi.org/10.1111/1467-6486.00384

Elsaied, M. M. (2019a). Supportive leadership and EVB: The mediating role of employee advocacy and the moderating role of proactive personality. Management development, 38(3), 225-237. https://doi.org/10.1108/JMD-04-2018-0119

Elsaied, M. M. (2019b). Supportive leadership, proactive personality and employee voice behavior: The mediating role of psychological safety. American Journal of Business, 31(1), 2-18. https://doi.org/10.1108/AJB-01-2017-0004

Farooq, N., Rehman, A., Bilal, H., Saleem, K., Hussain, A., \& Zeeshan, M. (2020). Proactive personality, motivation and employee creativity in the public sector hospitals of Peshawar City. International Review of Management and Marketing, 10(3), 16-21. https://doi.org/10.32479/irmm.9510

Fu, H., Ye, B. H., \& Xu, X. (2020). The cross-level effect of shared leadership on tourism employee proactive behavior and adaptive performance. Sustainability, (12), 617-627. https://doi.org/10.3390/su12020617

Ghitulescu, B. (2018). Psychosocial effects of proactivity the interplay between proactive and collaborative behavior. Personnel Review, 47(2), 294-318. https://doi.org/10.1108/PR-08-2016-0209

Gloet, M., \& Samson, D. (2020). Supporting supply Chain innovation and sustainability practices through knowledge and innovation management. Proceedings of the 53rd Hawaii International Conference on System Sciences, 4838-4847. https://doi.org/10.24251/HICSS.2020.594

Guan, X.-H., \& Huan, T.-C. (2018). Talent management for the proactive behavior of tour guides. International Journal of Contemporary Hospitality Management, 31(10), 4043-4061.

Huan, T.-C., \& Guan, X.-H. (2019). Talent management for the proactive behavior of tour guides. International Journal of Contemporary Hospitality Management. https://doi.org/10.1108/IJCHM-07-2018-0596

Ibidunni, A. (2020). Exploring knowledge dimensions for improving performance in organizations. Journal of Workplace Learning, 32(1), 76-93. https://doi.org/10.1108/JWL-01-2019-0013

Jiang, W., \& Gu, Q. X. (2015). A moderated mediation examination of proactive personality on employee creativity: A person environment fit perspective. Journal of Organizational Change Management, 28(3), 393-410. https://doi.org/10.1108/JOCM-05-2014-0088

Koenig, M. (2008). The origins and development of knowledge management. Journal of Information \& Knowledge Management (JIKM), 7(4), 243-254.

Liao, S., Van der Heijden, B., Liu, Y., Zhou, X., \& Guo, Z. (2019). The effects of perceived leader narcissism on employee proactive behavior: Examining the moderating roles of LMX quality and leader Identification. Sustainability, (11), 659- 662.

Liu, G., Joyceko, W., Ngugi, I., \& Takeda, S. (2017). Proactive entrepreneurial behaviour, market orientation and innovation outcomes: A study of small-medium sized manufacturing firm in UK. European Journal of Marketing, 51(11/12), 1980-2001. https://doi.org/10.1108/EJM-11-2016-0663

Liu, W. (2010). I warn you because i like you: Voice behavior, employee identifications, and transformational leadership. The Leadership Quarterly, 21(1), 189-202.

Lucia, A., \& Leibsinger, R. (2000). Job merit models - developing measurements, planning policies and using tools. Egypt, Cairo: The Arab Company for Scientific Information (Shuaa).

Maher, A. (2013). Management principles between knowledge and skill. Egypt, Alexandria: University House.

Morrison, E. W., \& Phelps, C. (1999). Taking charge: Extra-role efforts to initiate workplace change. Academy of Management Journal, (42), 403-419.

Parker, S. K., \& Collins, C. G. (2010). Taking stock: Integrating and differentiating multiple proactive behaviors. Journal of Management, 36(3), 633-662.

Plomp, J., Tims, M., Akkermans, J., Khapova, N., Svethlana, J., Paul, G. W., \& Bakker, A. B. (2016). Career competencies and job crafting: How proactive employee influence their well-being. Career Development International, 21(6), 587-602. https://doi.org/10.1108/CDI08-2016-0145. 
Ponisciakova, O. (2020). Knowledge management and its application in human resources management in the context of globalization. Globalization and its Socio-Economic Consequences, 74(2), 2-7.

Qandil, A., Awj, N., Al-Tarfi, A., \& Al-Shamri, A. (2020). The role of smart organization characteristics in enhancing entrepreneurial preparedness by adopting proactive work behaviors. Iraqi Journal of Management Sciences, 15(61), 271-309.

Robbins, S. P., \& Judge, T. (2015). Organizational behavior. UK.

Robert, B., Richard, W., \& Vess, J. (2020). The role of nontechnical skills in providing value in analytics-based decision culture. Journal of Education for Business. https://doi.org/10.1080/08832323.2020.1719961

Roopak, K., Mishra, S. K., \& Sikarwar, E. (2019). Linking leader-follwer proactive personality congruence to creativity. Personnel Review, 48(2), 454-470. https://doi.org/10.1108/PR-11-2017-0332

Saudi, M. (2020). Institutional capacity building as a change in planning for crisis and disaster management at Assiut University. Journal of Studies in Social Work and Human Sciences, 49(3), 613-658.

Srikanth, I. (2019). Developing human resource competencies: An empirical evidence. Human Resource Development International, 22(4), 343-363.

\section{Copyrights}

Copyright for this article is retained by the author(s), with first publication rights granted to the journal.

This is an open-access article distributed under the terms and conditions of the Creative Commons Attribution license (http://creativecommons.org/licenses/by/4.0/). 